\title{
Endometriumda Liesegang halkaları: Olgu sunumu ve literatürün gözden geçirilmesi
}

\author{
Liesegang rings in the endometrium: A case report and review of the literature \\ Handan Aker, Ayşe Akbulut Çiçekli, Tülay Koç, Hatice Özer*, Ali Yanık \\ Patoloji Anabilim Dalı (Prof. Dr. H. Aker, Dr. A. A. Çiçekli, Dr. T. Koç, Doç Dr. H. Özer), Kadın \\ Hastalıkları ve Doğum Anabilim Dalı (Prof. Dr. A. Yanık), Cumhuriyet Üniversitesi Tıp Fakültesi, \\ TR-58140 Sivas
}

\begin{abstract}
Özet
Endometrial kalsifikasyonlar benign ve malign lezyonlarda saptanabilmektedir. Ancak çeşitli organlarda farklı patolojik olaylara eşlik eden, histolojik ve sitolojik materyallerde saptanabilen, kalsiyum içermekle birlikte farklı kimyasal özelliklere sahip Liesegang halkaları olarak tanımlanan konsantrik lamellöz yapılar endometriumda oldukça az görülmekte ve tanı sorunlarına yol açabilmektedir. Postmenopozal kanama nedeniyle uzun süre hormon kullanan 76 yaşındaki bir hastanın endometriumunda saptadığımız hormonal değişiklikler yanısıra nadir görülen Liesegang halkaları literatür eşliğinde değerlendirilerek sunuldu.
\end{abstract}

Anahtar sözcükler: Endometrium, Liesegang halkaları

\begin{abstract}
Endometrial calcifications could be detected in a variety of benign and malignant lesions. However, Liesegang rings are defined as concentric laminated structures seen in different pathological events in various organs in the body, and can also be detectable in histological and cytological materials, include calcium with different chemical properties, and they are quite a few in the endometrium and may lead to diagnostic problems. Liesegang rings, which are quite rare in the endometrium, besides the hormonal changes of a 76-year-old postmenopausal patient using hormone for a long time due to her bleeding was presented and reviewed the literature.
\end{abstract}

Keywords: Endometrium, Liesegang rings

Geliş tarihi/Received: 08 Şubat 2014; Kabul tarihi/Accepted: 19 Ağustos 2014

\author{
*İletişim adresi: \\ Dr. Hatice Özer, Patoloji Anabilim Dalı, Cumhuriyet Üniversitesi Tıp Fakültesi, TR-58140 Sivas. \\ E-posta: haticozer@gmail.com
}

\section{Giriş}

Liesegang halkaları ilk kez 1896 yılında Alman biyokimyacı Raphael Eduard Liesegang tarafından tanımlanmış, tıp alanında ise 1987 yılından sonra çeşitli organlarda ve aspiratlarda varlığı bildirilmiştir. Genellikle yuvarlak halka benzeri nadir görülen bu yapılar amorf santral korun etrafında konsantrik tabakalarla çevrili, asellüler, eozinofilik ya da bazofilik boyanabilen laminer yapılardır. Bulundukları yere bağlı olarak içeriği değişebildiğinden tam olarak yapısı belirlenememiştir. Genellikle yoğun inflamasyonlu, kistik, hemorajik ve nekrotik dokularda tesbit edilmiştir [1-13]. Bununla birlikte laktasyonel değişiklikler gösteren meme dokusunda saptanan bir olgu nedeniyle kistik ve iltihabi olmayan dokularda da gelişebileceği bildirilmiştir [4]. Malign tümörlerde varlığına ait biri böbreğin berrak hücreli tümöründe, diğeri kadın genital sisteminde overde endometriotik kiste eşlik eden iyi diferansiye bir endometrioid adenokarsinom olgusunda olmak üzere iki olguda tanımlanmıştır $[6,11,13]$. 
En sık böbrek olmak üzere sinovya, meme, konjunktiva ve göz kapağı, maksiller ve paranazal sinusler, ağız tabanı, plevra, periton, perikard, omentum, tuba uterina, endometrium ve epididimde bulunmuştur. Erişkin parazitler, yumurta ve larvaları, psammom cisimleri, korpora amilasea, Michaelis-Guttman cisimleri, hyalin globüller, mukopolisakkarit, amiloid, müsin depozitleri ile karıştırılabilir [1-13].

Liesegang halkaları kadın genital sisteminde sekizi endometriumla, ikisi tubalarla ilişkili 10 olguda tesbit edilebilmiştir $[6-9,11,12]$. Burada postmenopozal kanama nedeniyle endometrial hiperplazi saptanan ancak sistemik hastalıkları nedeniyle hemen opere edilemeyen ve yaklaşık 8 ay olmak üzere uzun süre hormon tedavisi gören 76 yaşındaki hastanın endometriumunda saptadığımız etyopatogenezi tartışmalı nadir görülen Liesegang halkaları sunulmaktadır.

\section{Olgu sunumu}

Hipertansiyon, diabetes mellitus, koroner arter hastalığ 1 ve hiperkolesterolemisi olan 25 yıldır menopozlu 76 yaşındaki hasta kanama nedeniyle dış merkeze başvurmuştur. G10, P10 ve A0 olan hastanın endometrium kalınlığı $38 \mathrm{~mm}$ olarak tesbit edilmiştir. Endometrial küretaj ile basit atipisiz endometrial hiperplazi tanısı konulan hastaya linestrenol tedavisi başlanmıştır.

Hasta, tanısından 4 ay sonra tekrar başlayan kanama nedeniyle hastanemiz Kadın Hastalıkları ve Doğum Anabilim Dalı polikliniğine başvurdu, yapılan muayenesinde endometrium kalınlığ $20 \mathrm{~mm}$ olarak saptandı. Altı $\mathrm{mL}$ olan endometrial küretaj materyalinin histopatolojik değerlendirmesinde hiperplazi bulgularının ortadan kalktığı ancak endometriumda ilaç etkisi yanı sıra eozinofilik ve müsinöz metaplazi alanlarının yer aldığı saptandı. Bu arada hastaya koroner anjiografi ve acil kolesistektomi uygulandi. Üç ay sonra kontrole gelen, ilaçlarını düzensiz kullandığı ve 15 gündür devam eden vaginal kanaması olduğu öğrenilen hastanın endometrium kalınlığı da $17 \mathrm{~mm}$ olarak ölçüldü. Endometrial küretaj materyalinde ilaç etkisi süren hastanın ilaçları kesildi, 1,5 ay sonra yeniden vajinal kanama başlaması nedeniyle yapılan ultrasonografide kavite içinde $62 \times 70 \mathrm{~mm}$ boyutlarında düzensiz yapı tesbit edidi, $40 \mathrm{~mL}$ olan küretaj materyalinde fokal ilaç etkisi yanı sıra endometrial polipe ait doku tesbit edildi. Bir ay sonra yapılan kontrol küretajında fokal ilaç etkisi ve polip varlığının sebat ettiği görüldü. Küretaj materyallerinin hepsinde endometriumda miktarları giderek artan oranda stroma, gland lümenleri ve epitelinde yer alan bazıları düzensiz, bazıları yuvarlak, eozinofilik ve bazofilik boyanmalar gösteren, genelde çift çeperli, orta kısımlarında yoğun boyanan, çevrelerinde konsantrik halka yapılarının seçildiği cisimcikler dikkati çekti, ancak çevresinde iltihabi reaksiyon saptanmadı (Resim 1, 2, 3). Bu halkalar kalsifikasyonlardan farklı yapısal özelliğe sahip olduğundan Liesegang halkaları olarak değerlendirildi ve patogenezine yönelik Von Kossa ve PAS boyamaları yapıldı. Von Kossa negatif, PAS pozitif (Resim 4) olarak değerlendirildi. Hastanın kan kalsiyumu da 9,6 mg/dL olarak saptand. Kanamanın devam etmesi nedeniyle frozen eşliğinde TAH ve BSO uygulanan hastada endometriumda $2,5 \mathrm{~cm}$ uzunluğunda ve $1,5 \mathrm{~cm}$ çapında sapı bulunan $5,5 \times 5 \times 3 \mathrm{~cm}$ boyutlarında yer yer kanamalı yumuşak elastik kıvamlı 1 adet polipoid yapı yanı sıra endometriumun düzensiz nodüler yapıya sahip olduğu izlendi (Resim 5a, b). Histopatolojik incelemede; endometrial polibin yer aldığı malignite saptanmayan endometriumda ilaç etkisinin ortadan kalktığı dikkati çekti. 


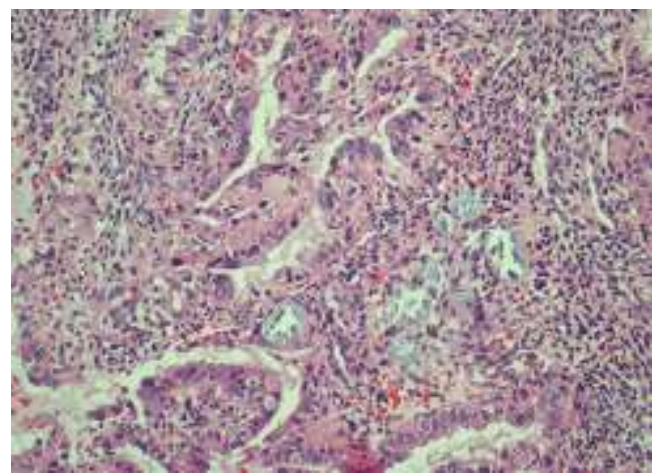

Resim 1. Endometrial gland epitelinde ve stromada bazofilik, değişik büyüklükte yer alan Liesegang halkaları (H\&E: x10).

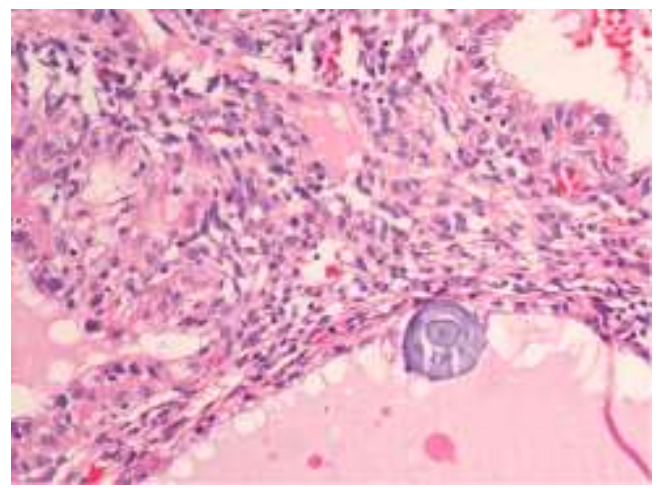

Resim 2. Endometrial gland lümeninde nidus benzeri santral matriks çevresinde bazofilik boyanan konsantrik laminasyon gösteren Liesegang halkası (H\&E: x20).

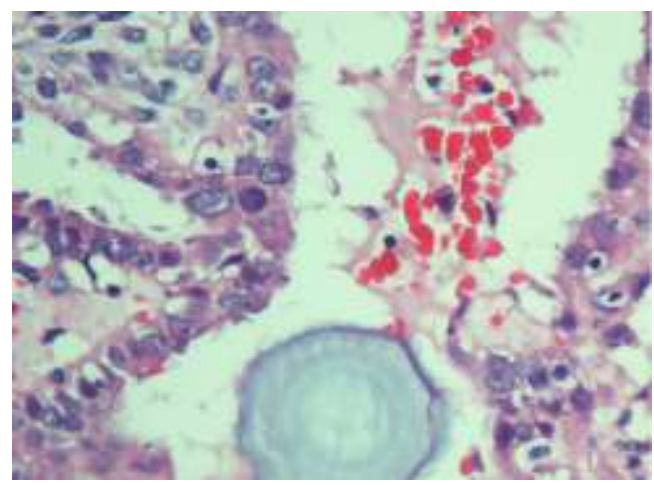

Resim 3. Gland lümeninde yer alan dış çeperi belirgin, laminasyon gösteren Liesegang halkaları (H\&E: x40).

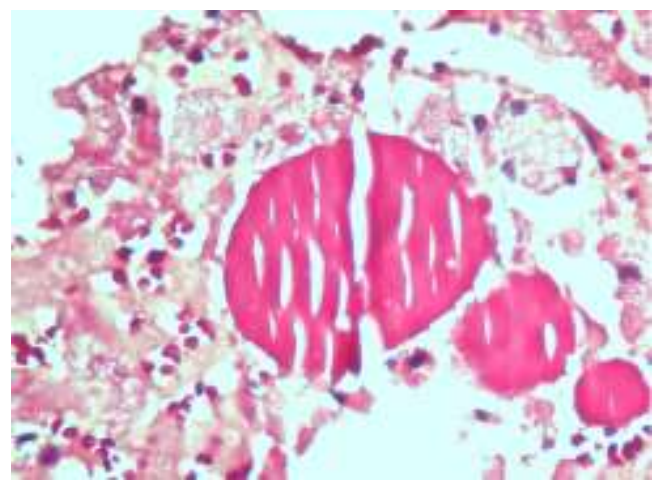

Resim 4. Liesegang halkası (PAS: x40). 

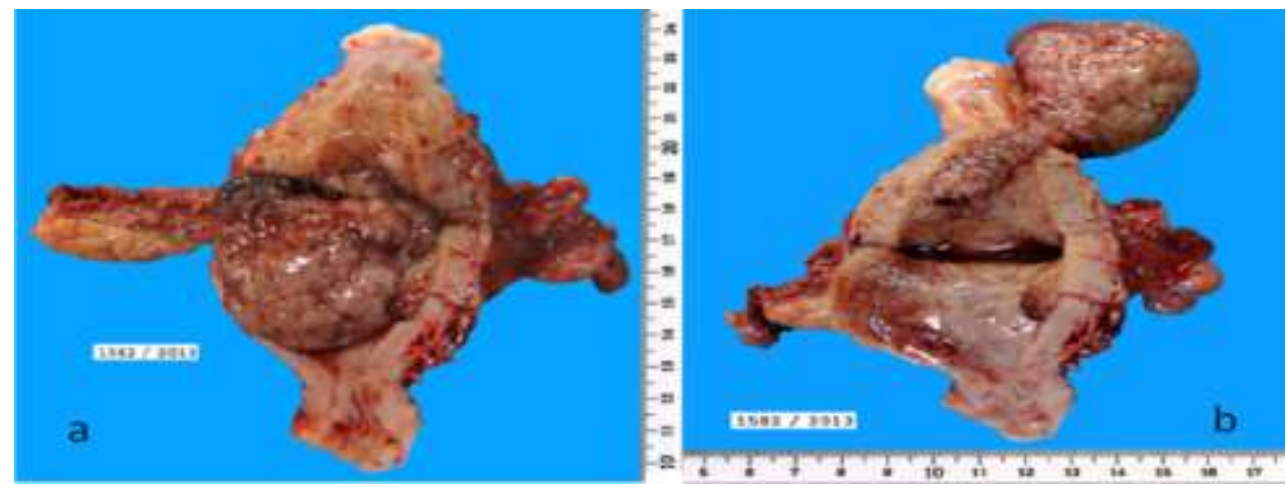

Resim 5 a, b. Kaviteyi dolduran, ön duvara sapla tutunan yer yer kanamalı, elastik kıvaml, gri-pembe renkte endometrial polip.

\section{Tartışma}

Endometrial dokuda kalsifikasyonlar küretaj gibi cerrahi işlemler ve düşük sonrası veya rahim içi araç (RİA) kullanım öyküsü olanlarda gelişebilen enfeksiyonlarla ilişkili olarak çeşitli benign ya da endometrial papiller seröz karsinom gibi malign olaylarda izlenebilmektedir. Ayrıca RİA kullanımına bağlı, uterin prolapsus ve sistosel nedeniyle yapılan histerektomi materyallerinde endometriyumda kalsifiye cisimcikler bildirilmiştir $[6,7,9,11]$.

Literatürde kadın genital sistemi ile ilişkili Liesengang halkalarının görüldüğü dokuz olgu saptanmıştır $[6,8,9,11,12]$. Buna göre biri endometriotik kist zemininde gelişen belirgin skuamöz metaplazi gösteren iyi diferansiye endometrioid adenokarsinomda olmak üzere beş olgu overdeki endometriotik kistlerde $[9,11]$, bir olgu intraperitoneal endometriotik implantta [12], iki olgu tubalarda [8,9] ve bir olgu paratubal kistte [6] yer almaktadır. Türk literatüründe ise endometriumda saptanan bir olgu bulunmuştur [7].

Liesegang halkalarının endometriozis gibi hemorajik kistlerde tesbit edilmesi bir ilişkinin varlığını düşündürmekle birlikte sık görülen endometriozislerde az bulunması nedeniyle oluşumu için gerekli faktörlerin endometriozislerde her zaman bulunmadığı varsayılabilir. Oluşumunda genel olarak kolloidal matriks içinde ritmik sub veya supersature insolubl ürünlerin diffüzyonla presipitasyonunun rol oynadığ $1,1 \mathrm{~s} 1, \mathrm{pH}$, konsantrasyon, şarj gibi çeşitli fizikokimyasal faktörlerin etkili olabileceği belirtilmiştir [1].

Kalsifikasyonlar genel olarak düzensiz ya da psammom cisimleri gibi düzenli konsantrik laminasyonlar şeklinde görülebilir. Liesegang halkaları ise hücre içermeyen, genellikle yuvarlak, 3-800 $\mu \mathrm{m}$ boyutlarında, çoğunun çift katlı dış duvarı ve amorf santral nidusu bulunan, radyal striasyonlu konsentrik lameller yapılardır. Çoğu büyük bir halka içinde küçük birçok halkaya sahiptir. Halkalar polarize 1şıkta birefranjan göstermemektedir. Hücre içinde, gland lümenlerinde ve stroma da yer alabilmektedir. Liesegang halkalarının Papanicolaou, H\&E, Masson trichrome, asid-fast ve gram boyaları ile morfolojik detayları iyi seçilmekte, Diff-Quik boyasında ise koyu mor boyanmakla birlikte konsantrik laminar yapısı iyi belirlenememektedir. Bu halkaların çevresinde iltihabi reaksiyon izlenmemiştir [1-13].

Transmisyon elektronmikroskopik ve X-ray difraksiyon ile yapılan bir araştırmada halkaların organik bir yapıya sahip olduğu gösterilmiştir [1]. Ancak bazı olgularında kalsiyum, demir, sülfür ve silikon içerdiği tesbit edilmiştir. Bununla birlikte bazı halkaların Von Kossa, Alizarin red, Prusya mavisi, Grocott'un metanamin gümüş nitratı, Alcian blue, Congo red ve PAS boyaları ile boyanmadığı, bazılarının ise PAS ile boyandığı, kalsiyum negatif olgular yanı sıra kalsiyum oksalat kristallerinin saptandığ1 şeklinde birbiriyle çelişkili sonuçlar bildirilmektedir [1-13]. İmmünhistokimyasal olarak keratin (AE1/AE3), epitelyal membran antijen (EMA) ve hemoglobine yönelik araştırmalarda da boyanma tesbit edilmemiştir $[1,3]$. 
Sonuç olarak farklı patolojik olaylara eşlik eden Liesegang halkalarının farklı kimyasal özelliklere sahip olduğu, farklı kimyasal bileşimlerin lokal çevresel faktörlere bağlı olarak değişebileceği varsayılabilir. Olgumuzda Von Kossa ile negatif, PAS ile pozitif boyanma tesbit edilmiştir.

Liesegang halkalarının tanısı zor olabilir. Sitolojik örneklerde nadiren görülür. Dioctophyma renale veya Echinococcus gibi parazitler, Trichuris trichiura dejenere larvaları, psammom cisimciği, korpora amilasea, Michaelis-Guttman cisimciği, hyalin globüller, keratin, amiloid ve müsin depozitleri ile ayırıcı tanıların yapılması gerekebilir. Liesegang halkalarına benzer konsantrik laminasyonlar gösteren korpora amilasea ve Michaelis-Guttman cisimciklerinin oluşum teorilerinde korpora amilaseaların MichaelisGuttman cisimciklerinin gibi doku spesifik olduğu ancak korpora amilaseaların genelde inflamasyon ve kistik oluşumlara eşlik etmediği, kimyasal yapılarının kalsiyumdan oluştuğu, Michaelis-Guttman cisimciklerinin ise demir, fosfor ve kalsiyum içerdiği belirtilmektedir. Malokoplaki tanısı için patognomonik olan Michaelis-Guttman cisimcikleri intrasitoplazmik gram negatif çubuklar içeren histiositlerdir. Bunlar PAS ile negatif, Von Kossa pozitif reaksiyon verir. Bazofilik boyanan psammom cisimleri de kalsiyum içerir $[1,3,8]$.

Hastamız 25 yıldır menopozda olup hipertansiyon, koroner kalp hastalığı, hiperlipidemi, diabet gibi sistemik hastalıkları nedenleriyle antihipertansif ilaçlar, oral antidiyabetik ajanlar, antihiperlipidemik ilaçlar, non-steroidal antiinflamatuar ilaçlar ve proton pompa inhibitörü gibi çeşitli ilaçlar yanı sıra uzun süre progestin kullanmıştır. Postmenopozal kanamalı hastalarda kanama nedenleri arasında atrofik endometriyum (\%60-80), eksojen hormon tedavisi (\%15-25), endometriyal hiperplazi (\%5-10), endometriyal/servikal polip (\%2-12) ve endometriyum kanseri (\%10) yer almaktadır. Bunun yanı sira servisit, atrofik vajinit, vulva, vajen ve serviks kanserleri, uterus sarkomları ve over kanserlerine bağlı kanamalar da görülebilir [14]. Hastamızda öncelikle basit atipisiz endometrial hiperplazi kanama nedeni olarak ortaya çıkmış, hormon tedavisine bir süre cevap veren hastada endometrial polipe bağlı tekrarlayan kanamaların artması nedeniyle malignitenin ekarte edilmesi amaciyla total abdominal histerektomi ve bilateral salpingo-ooferektomi uygulanmıştır. Ekzojen hormonların endometriumdaki etkileri ilacın kullanım şekline, süresine, dozuna ve içeriğine bağlı olarak değişebilmektedir. Uzun dönemde atrofik glandlar ve desidualize stroma ile karakterli değişiklikler ortaya çıkar. Stromada mikrokalsifikasyonlar, hyalen nodüller, müsinöz veya mikzoid değişiklikler yanısıra glandüler metaplastik değişiklikler ve polipoid gelişimler izlenebilir [15-17]. Nitekim hastamızda ilaca bağlı olarak belirtilen stromal ve glandüler değişiklikler yanı sıra Liesegang halkaları dikkati çekmiştir.

Liesegang halkaları bulunan bir kısım hastada endometriozis, desensus uteri, Asherman sendromu, kombine oral kontraseptif, RİA kullanımı öyküleri bulunmaktadır [6, 7, 9, 11, 12]. Hastada sistemik metabolik hastalıklar ve bunlar için kullandığı çok sayıda ilaç yanı sıra uzun süre hormon kullanım öyküsü vardır. Kan kalsiyum düzeyi normal sınırlarda olan hastada halkaların oluşumunda endometriyal sekresyonun presipitasyonu ile distrofik kalsifikasyon sorumlu olabilir.

Sonuç olarak; endometriyumda ilaca bağglı değişiklikler arasında sayılan sekretuar, AriasStella reaksiyonu gösteren glandlar, desidualize stroma, kribriform papiller yapıda glandlar, epitelde ülserasyon ve nekroz, glandüler eozinofilik, müsinöz, papiller metaplastik değişiklikler, mikrokalsifikasyonlar, kalsifiye düzensiz çöküntüler yanı sıra Liesang halkalarının varlığı da dikkate alınmalıdır. Liesegang halkaları için çift çeperli karakteristik konsantrik laminasyon ve radiyal kros çizgilenmeler tanısaldır. Esas olarak benign lezyonlara eşlik eden bu halkaların varlığında malignite olasılığı da ekarte edilmelidir. 


\section{Kaynaklar}

1. Raso DS, Greene WB, Finley JL, Silverman JF. Morfology and patogenesis of liesegang rings in cyst aspirates: Report of two cases with ancillary studies. Diagn Cytopathol 1998; 19: 116-9.

2. Erkul ZK, Erkuş M, Taşkın F, Meteoğlu İ. Meme biyopsisinde Liesegang ring kalsifikasyon: Olgu sunumu. Meme Sağlığı Dergisi 2005; 1: 22-4.

3. Sneige N, Batsakis JG, Hawkins RA, Doble PH. Pseudoparasitic (Liesegang) bodies in paranasal sinüs. J Laryngol Otol 1988; 102: 730-32.

4. Islam MT, Ou JJ, Hansen K, Simon RA, Quddus MR. Liesegang-like rings in lactational changes in the breast. Case report. Case reports in Pathology 2012.

5. Pegas KL, Edelweiss MI, Cambruzzi E, Zettler CG. Liesegang rings in Xanthogranulomatous pyelonephritis: A case report. Pathology Res Int 2010.

6. Luna DV. Liesegang Rings in Paratubal Cysts: Case Report and Literature review. Int J Gynecol Pathol 2010; 29: 335-8.

7. Topal N, Kırımca F, Yörükoğlu K. Endometrial kalsifikasyon ve Liesegang halkalar1. Patoloji Bülteni 2001; 18: 54-6.

8. Tuur SM, Nelson AM, Gibson DW. Liesegang rings in tissue-How to distinguish Liesegang rings from the giant kidney worm, Dioctophyma renale. Am J Surg Pathol 1987; 11: 598-605.

9. Clement PB, Young RH, Scully RE. Liesegang rings in the female genital tract. A report of three cases. Int J Gynecol Pathol 1989; 8: 271-6.

10. Padwell A. Liesegang rings associated with a cystic lesion of the eyelid. Br J Ophtalmol 1995; 78: 706-7.

11. Perrota PL, Ginsburg FW, Siderides CI, Parkash V. Liesegang rings and endometriosis. Int J Gynecol Pathol 1998; 17: 358-62.

12. Schwartz DA, Bellin HJ. Liesegang rings developing within intraperitoneal implants. A case report. J Reprod Med 1991; 36: 403-6.

13. Santos-Briz JR, Serrano R, Canizo A, Santos-Briz A, Agustin PP. Liesegang rings in a dermoid cyst of the floor of the mouth. Acta Cytol 2000; 44: 1062-5.

14. Reid PC, Brown VA, Fothergill DJ. Outpatient investigation of postmenopausal bleeding. Br J Obstet Gynecol 1993; 100: 498.

15. Cohen I. Endometrial pathologies associated with postmenopausal tamoxifen treatment. Gynecol Oncol 2004; 94: 256-66.

16. Bentley RC, Robboy SL. Exogenous hormones and their effects on the endometrium. In: Robboy SL, Ed. Robboy's Pathology of the Female Genital Tract. Elseiver 2009: 325-41.

17. Mutter GL, Nucci MR, Robboy SL. Endometritis, metaplasias, polyps and miscellaneous changes. In: Robboy SL, Ed. Robboy's Pathology of the Female Genital Tract. Elseiver 2009: 343-66. 